\title{
Leucomycin $A_{3}$, a 16-membered macrolide antibiotic, inhibits influenza $A$ virus infection and disease progression
}

\author{
Ryuichi Sugamata ${ }^{1,2}$, Akihiro Sugawara ${ }^{3}$, Tomokazu Nagao ${ }^{1,2}$, Koya Suzuki ${ }^{1}$, Tomoyasu Hirose ${ }^{3}$, \\ Ki-ichi Yamamoto ${ }^{2}$, Masamichi Oshima ${ }^{2}$, Kazuo Kobayashi ${ }^{2}$, Toshiaki Sunazuka ${ }^{3}$, Kiyoko S Akagawa ${ }^{2,3}$, \\ Satoshi Ōmura ${ }^{3}$, Toshinori Nakayama ${ }^{4}$ and Kazuo Suzuki ${ }^{1,2}$
}

Severe respiratory disease arising from influenza virus infection has a high fatality rate. Neutrophil myeloperoxidase (MPO) has been implicated in the pathogenesis of severe influenza-induced pneumonia because extracellularly released MPO mediates the production of hypochlorous acid, a potent tissue injury factor. To search for candidate anti-influenza compounds, we screened leucomycin $A_{3}\left(L M-A_{3}\right)$, spiramycin (SPM), an erythromycin derivative (EM900, in which anti-bacterial activity has been eliminated), and clarithromycin (CAM), by analyzing their ability to inhibit MPO release in neutrophils from mice and humans. When each candidate was injected into mice infected with a lethal dose of A/H1N1 influenza virus (PR-8), LM- $A_{3}$ produced the highest survival rate (80.9\%). We found that $\mathrm{LM}-\mathrm{A}_{3}$ induced beneficial effects on lung pathology and viral proliferation involved in the regulatory activity of MPO release, pro-inflammatory cytokines and interferon- $\alpha$ production in the lung. SPM and EM900 also induced positive survival effects in the infected mice, whereas CAM did not. We further found that these compounds inhibit virus proliferation in human pneumonia epithelial $A 549$ cells in vitro. LM- $A_{3}$ showed effective action against influenza $A$ virus infection with high anti-viral activity in human host cells, indicating the possibility that $L M-A_{3}$ is a prospective lead compound for the development of a drug for human influenza. The positive survival effect induced by EM900 suggests that pharmacological architectures between anti-bacterial and anti-influenza virus activities can be dissociated in macrolide derivatives. These observations provide valuable evidence for the potential development of novel macrolide derivatives that have strong anti-viral but no anti-bacterial activity.

The Journal of Antibiotics (2014) 67, 213-222; doi:10.1038/ja.2013.132; published online 5 February 2014

Keywords: 16-membered macrolide; anti-viral; clarithromycin; EM900; influenza virus; leucomycin $\mathrm{A}_{3}$; MPO

\section{INTRODUCTION}

Influenza is an acute viral infection that can spread easily from person to person. Influenza viruses circulate worldwide and anybody in any age group is at risk of infection. Influenza causes annual epidemics that peak during winter, frequently leading to an increase in hospitalizations and number of deaths, especially among the elderly and infants. ${ }^{1,2}$ The occurrence of an influenza epidemic has often led to huge loss of life. The Spanish influenza (A/H1N1) of 1918 resulted in a worldwide pandemic that caused massive devastation, with an estimated 20-50 million deaths. ${ }^{3,4}$ In 1997, a highly pathogenic avian influenza (A/H5N1) virus was first recognized to be capable of infecting humans, since then, sporadic human infections with this virus have shown over $60 \%$ fatality. ${ }^{5,6}$ Today, there have been many cases of human infection with newly emerged virulent strain of avian influenza (A/H7N9 virus), which has spread rapidly in China (http:// www.who.int/influenza/human_animal_interface/influenza_h7n9/en/). A severe respiratory disease has also been observed in patients infected with avian influenza viruses as well as in non-human primates infected with a reconstructed Spanish influenza virus. ${ }^{4,8}$ In 2009, a novel influenza virus $(\mathrm{A} / \mathrm{H} 1 \mathrm{~N} 1 \mathrm{pdm})$ emerged as a highly contagious strain and triggered the most recent global pandemic. Several cases of severe respiratory disease evoked by the pandemic virus were reported. ${ }^{9,10}$ Influenza-induced severe respiratory disease has a high fatality rate, resulting from respiratory disorder and failure. Even emergency treatment by extracorporeal membrane oxygenation for such respiratory failure has poor outcomes in Japan (35\% survival rate), ${ }^{11}$ indicating that the current medical approach is minimally effective for patients with influenza-induced respiratory failure.

\footnotetext{
${ }^{1}$ Inflammation Program, Graduate School of Medicine, Chiba University, Chiba City, Japan; ${ }^{2}$ Department of Immunology, National Institute of Infectious Diseases, Shinjuku-ku, Japan; ${ }^{3}$ The Kitasato Institute, Kitasato Institute for Life Sciences and Graduate School of Infection Control Sciences, Kitasato University, Minato-ku, Japan and ${ }^{4}$ Department of Immunology, Graduate School of Medicine, Chiba University, Chiba City, Japan

Correspondence: Professor K Suzuki, Inflammation Program, Department of Immunology, Graduate School of Medicine, Chiba University, Inohana 1-8-1, Chuo-ku, Chiba City, Chiba 260-8670, Japan.

E-mail: ksuzuki@nih.go.jp

Received 6 June 2013; revised 16 October 2013; accepted 10 November 2013; published online 5 February 2014
} 
Therefore, the development of anti-influenza agents that reduce the lethality due to severe pneumonia and viral load are urgently required.

Clinically used anti-viral drugs, such as oseltamivir and zanamivir, are beneficial for human influenza. ${ }^{12}$ These neuraminidase inhibitors interfere with viral proliferation during the acute phase of the infection. ${ }^{13}$ Of concern is that several recent observations have recognized a striking increase in drug-resistant $\mathrm{A} / \mathrm{H} 1 \mathrm{~N} 1$ viruses that are currently causing an increasing problem worldwide. ${ }^{14,15}$ In addition, a synaptic interference is also suspected to be an unwanted side effect of oseltamivir. ${ }^{16}$ New neuraminidase inhibitors, peramivir and laninamivir, are now being prescribed as alternate drugs. However, it should be recognized that it is only a matter of time until viruses resistant to these drugs emerge.

It was reported that clarithromycin (CAM), a 14-membered macrolide antibiotic, is effective in influenza virus infection, even though it is an anti-bacterial drug. ${ }^{17}$ The anti-influenza virus and anti-inflammatory activities of CAM have been supported by both in vivo and in vitro studies. ${ }^{18-20}$ In spite of this, a recent clinical trial treating with a combination of CAM and oseltamivir showed limited effect in patients infected by seasonal influenza A virus, ${ }^{21}$ suggesting that CAM has little effect as an anti-influenza drug. In addition, CAM displays anti-influenza virus and anti-inflammatory properties alongside its direct anti-bacterial effects. ${ }^{20}$ This means that CAM use carries a high risk of promoting evolution of drug-resistant bacterial pathogens. Macrolide compounds possessing effective antiinfluenza virus and anti-inflammatory activities, but devoid of any anti-bacterial activities, would therefore appear to be the best leads for the development of optimal anti-influenza drugs.

Infection with influenza viruses induces neutrophil infiltration into the airway and the alveoli of the lung. ${ }^{22}$ The neutrophils phagocytose the apoptotic cells infected by the influenza virus and degrade viral proteins inside the phagosomes via the activity of myeloperoxidase (MPO) contained in azurophilic granules. ${ }^{22,23}$ These findings indicate that the neutrophils contribute to viral clearance and limitation of viral spread in the lung. However, the activated neutrophils exocytose azurophilic granules, including MPO, by degranulation. ${ }^{24,25}$ The extracellularly released MPO mediates the production of reactive oxygen species, including hypochlorous acid, which are potent tissue injury factors. ${ }^{24}$ Therefore, excessive recruitment of the neutrophils retaining MPO has been suggested to be associated with pathogenesis of severe respiratory disease induced by influenza $\mathrm{A} / \mathrm{H} 1 \mathrm{~N} 1$ and $\mathrm{A} /$ H5N1 viruses. ${ }^{26-28}$ Previously, we elucidated, using MPO-deficient mice, that the absence of MPO activity shows a tendency to decrease severe inflammation and viral load in the lung during a lethal infection with $\mathrm{A} / \mathrm{H} 1 \mathrm{~N} 1$ virus. $^{29}$ It is thus possible that an inhibitor of MPO release from the activated neutrophils could significantly alleviate severe pneumonia and viral load during an influenza A virus infection.

In this study, we report the results of our search for macrolide candidates showing good efficacy with respect to the impact that antiinfluenza virus and anti-inflammatory has, focusing on the inhibitory effect on MPO release from activated neutrophils. The inhibitors of MPO release were selected from the Kitasato Institute macrolide compound library by analyzing their ability to inhibit MPO release in neutrophils in vitro, and evaluating their efficacy in the treatment of influenza-induced disease using a mouse model lethally infected with influenza $\mathrm{A} / \mathrm{H} 1 \mathrm{~N} 1$ virus.

\section{MATERIALS AND METHODS}

Macrolide compound library

Since the 1980s, the research group at the Kitasato Institute has been investigating the various properties of 14- and 16-membered macrolides (such as erythromycin, tylosin, spiramycin (SPM) and leucomycin (LM)), evaluating anti-bacterial, gastrointestinal motor-stimulating activity and anti-inflammatory and/or immunomodulatory properties, including various derivatives synthesized from the parent compounds via chemical modification. The Kitasato Institute chemical library was used as a source of macrolide compounds used in this research.

\section{Evaluation of an inhibitory effect of macrolide derivatives on MPO release}

Mouse and human polymorphonuclear cells (PMNs) contain abundant neutrophils. Inhibitory effect of MPO release by macrolide compounds from human and mouse PMNs was measured using a modified TMB $\left(3,3^{\prime}, 5,5^{\prime}\right.$ tetramethylbenzidine) method. ${ }^{30}$ Human PMNs were isolated from the blood of healthy volunteers using polymorphprep (Axis-shield PoC AS, Oslo, Norway). Mouse PMNs were purified from the bone marrow of an 8-weekold BALB/c mouse by density gradient centrifugation with Percoll (GE Healthcare, Little Chalfont, UK). The protocols for human sample use and animal work were approved by the Institutional Ethics Committee, Graduate School of Medicine, Chiba University (AUP numbers 1035 and 22-265). Each macrolide compound was dissolved in dimethylsulfoxide to a final concentration of $<1 \%$ in a reaction Hank's balanced salt solution (HBSS; Gibco, Carlsbad, CA, USA) medium. Fifty thousand PMNs, pre-warmed for $10 \mathrm{~min}$ at $37^{\circ} \mathrm{C}$, were stimulated with $50 \mu \mathrm{l}$ of pre-warmed HBSS medium containing $5 \mu \mathrm{g} \mathrm{ml}^{-1}$ cytochalasin B and $10^{-6} \mathrm{M}\left(10^{-5} \mathrm{M}\right.$ for mouse PMNs) formylmethionyl-leucyl phenylalanine, in the presence or absence of each macrolide compound at the indicated concentration, in a V-bottom 96-well plate for $10 \mathrm{~min}$ at $37^{\circ} \mathrm{C}$. After stimulation, the cells were cooled using icy water and then centrifuged at $350 \mathrm{~g}$ for $5 \mathrm{~min}$ at $4{ }^{\circ} \mathrm{C}$ to separate into supernatant and cell pellet. The cell pellet was lysed with $0.1 \%$ Triton-X100 (phosphate-buffered saline (PBS)) for $5 \mathrm{~min}$ at room temperature. MPO activities in the samples were assayed as follows: the reaction mixture consisted of $10 \mu \mathrm{l}$ of the supernatant or the cell lysates, $7.2 \%$ dimethylformamide, $1.7 \mathrm{mM} \mathrm{TMB}$, $84.2 \mathrm{~mm}$ sodium citrate buffer ( $\mathrm{pH} 5.4$ ), $0.39 \mathrm{~mm} \mathrm{H}_{2} \mathrm{O}_{2}, \mathrm{PBS}(-)$ and HBSS in a total volume of $200 \mu \mathrm{l}$ in a flat-bottom 96-well plate. After mixing, increase in absorbance at $650 \mathrm{~nm}$ in the reaction mixture was measured at $37^{\circ} \mathrm{C}$ for $5 \mathrm{~min}$ with a Bio-Rad automatic reader system (Model 680microplate reader, Bio-Rad, Hercules, CA, USA). The activity was measured as units $\mathrm{min}^{-1} \mathrm{ml}^{-1}$. The rate of activity of extracellularly released MPO was calculated as a percentage release according to the following: (absorbance of supernatant/absorbance of supernatant + absorbance of cells pellet $) \times 100(\%)$. On the basis of this calculation, macrolide compounds that inhibit MPO release from human and mouse PMNs were screened.

\section{Mice}

Animal protocols associated with influenza virus infection were approved by the Institutional Animal Use and Care Committee and conformed to the guidelines of National Institute of Infectious Diseases (AUP number 111007 ). Wild-type, female, 8-week-old BALB/c mice were purchased from SLC (Shizuoka, Japan) and housed in pathogen-free conditions to prevent any secondary pathogenic infection.

\section{Virus}

A mouse-adapted strain of influenza virus, A/Puerto Rico/8/34 (PR-8, H1N1), was supplied by the National Institute of Infectious Diseases. The virus strain was propagated in embryonated hen's eggs and stored at $-80^{\circ} \mathrm{C}$ until use. The frozen virus was dissolved on ice and then centrifuged at 4000 r.p.m. for $5 \mathrm{~min}$ at $4{ }^{\circ} \mathrm{C}$. The supernatant was used as viral solution for the infection.

\section{Virus infection and administration of macrolides in mice}

To prepare macrolide diluents, each macrolide compound dissolved in $\mathrm{EtOH}$ was diluted with D-PBS and adjusted as follows: $250 \mu \mathrm{l}$ EtOH/D-PBS contained $66 \mu \mathrm{g}$ macrolide compound to a final concentration of EtOH/DPBS was $<4 \%$. An EtOH/D-PBS diluent without a macrolide compound was used as a control. The fresh macrolide-EtOH/D-PBS diluent or control was prepared and used for injection each time. 
Mice were lightly anesthetized with pentobarbital sodium by i.p. injection. The mice were intranasally infected with 320 plaque-forming units of PR-8 virus in $30 \mu \mathrm{l}$ of RPMI 1640 medium supplemented with $2 \%$ fetal bovine serum. Each infected mouse was i.p. injected with $250 \mu \mathrm{l}$ of macrolide-EtOH/ D-PBS diluent or control EtOH/D-PBS diluent at one injection per day between 0 and 5 days post infection. Mice were subjected to survival challenge with a daily body weight check for 14 days.

\section{Collection of bronchoalveolar lavage fluid}

Samples were collected under uniform experimental conditions. At 3 or 6 days post infection, mice were killed by terminal anesthesia and lavage fluid was freshly collected via the trachea by performing three lavages with $1 \mathrm{ml}$ of physiological saline solution. The fluid was pooled and spun at 1500 r.p.m. for $5 \mathrm{~min}$, the supernatant was then collected as bronchoalveolar lavage fluid (BALF) for the analyses of MPO activity and cytokine production.

\section{Histology and cDNA preparation of lung tissue}

After collection of the BALF, lung tissue was collected. A left lung lobe was removed and fixed with 10\% formalin neutral buffer solution (Wako, Osaka, Japan) for more than a week. The fixed tissue was embedded in paraffin, cut into 3- $\mu \mathrm{m}$-thick sections and stained by hematoxylin and eosin for histopathological observation. The dissected right lung lobe was fixed by RNAlater (Takara Bio, Shiga, Japan) for more than a week, and total RNA was extracted using an RNA extraction reagent (ISOGEN; Nippon Gene, Tokyo, Japan). The extracted RNA was treated with DNase (TURBO DNA-free; Ambion, Austin, TX, USA) and then $1 \mu \mathrm{g}$ of DNA-free total RNA was reverse transcribed into cDNA with Superscript VILO cDNA Synthesis Kit (Invitrogen, Carlsbad, CA, USA)

\section{Viral infection of human lung epithelial cells}

The A549 cells were maintained by passages with Dulbecco's modified Eagle's medium (Sigma Aldrich Japan, Tokyo, Japan) supplemented with 10\% fetal bovine serum (Mexico origin, Gibco) and 1\% penicillin/streptomycin (Gibco). The A549 cells were transferred into six-well plates and cultured until they formed confluent monolayers. The cells were washed twice with pre-warmed, non-supplemented HBSS (Gibco) to remove serum components from the well, and were then infected with 1000 plaque-forming units of the PR-8 virus in $500 \mu \mathrm{l}$ of serum-free pre-warmed Dulbecco's modified Eagle's medium for $1 \mathrm{~h}$ at $34^{\circ} \mathrm{C}$, with shaking for every $20 \mathrm{~min}$. After infection, the cells were washed three times with pre-warmed, non-supplemented HBSS and cultured with prepared $2 \mathrm{ml}$ macrolide-containing medium at $37^{\circ} \mathrm{C}$. Each macrolide compound was dissolved in $100 \% \mathrm{EtOH}$ and diluted with $2 \mathrm{ml}$ of the supplemented Dulbecco's modified Eagle's medium at the indicated concentration. EtOH without a macrolide compound was used as a control. The final concentration of EtOH was $<1 \%$ in the medium. After 2 or $48 \mathrm{~h}$, the culture supernatant was removed, A549 cells were washed with non-supplemented HBSS three times, and dissolved and collected using ISOGEN (Nippon Gene).

Total RNA, including PR-8 virus RNA in the A549 cells, was extracted using Ethachinmate (Wako) to reduce the loss of total RNA. One microgram of total RNA was reverse transcribed into cDNA with Superscript VILO cDNA Synthesis Kit (Invitrogen).

\section{Quantitative real-time PCR}

The relative expression level of influenza virus matrix 1 (M1) gene in the lung was quantified by real-time quantitative PCR with SYBR Green PCR Master Mix (Applied Biosystems, Foster City, CA, USA) using StepOne Real-Time PCR System (Applied Biosystems). The oligonucleotide primer pair for amplification of M1 was referred for a report ${ }^{31}$ as follows-forward: $5^{\prime}$-AAG ACCAATCCTGTCACCTCTGA- $3^{\prime}$ and reverse: $5^{\prime}$-CAAAGCGTCTACGCTG CAGTCC- $3^{\prime}$. The reaction PCR condition was $95^{\circ} \mathrm{C}$ for $15 \mathrm{~s}$ and $60^{\circ} \mathrm{C}$ for $1 \mathrm{~min}$, repeated for 40 cycles, with a hot start at $95^{\circ} \mathrm{C}$ for $10 \mathrm{~min}$. The expression level of virus M1 in the mouse lung was normalized by that of glyceraldehyde-3-phosphate dehydrogenase. The copy numbers of M1 nucleotide in the A549 cells were quantified by standard plasmid ligated with M1 nucleotide.

\section{Cytokine assay in BALF}

Mouse interferon- $\alpha($ IFN- $\alpha)$ proteins in the BALF were measured by ELISA Kit (PBL InterferonSource, Piscataway, NJ, USA), according to the manufacturer's instructions. Altogether, 32 kinds of cytokine and immune-related proteins in lung BALF collected from infected mice were exhaustively quantified by mouse Multi-plex analysis using Luminex (Millipore, Billerica, MA, USA) on the Bio-plex reader (Bio-Rad).

\section{Statistical analysis}

Survival curves were calculated by the Kaplan-Meier method, the log-rank (Mantel-Cox) test being used for statistical comparison of survival curves. Statistical differences of body weight between PBS- and macrolide-injected mice were calculated by non-parametric Mann-Whitney $U$-test. All other analysis was performed using a Student's $t$-test. Statistical analyses were performed with GraphPad Prism version 5 (GraphPad software, Inc., CA, USA).

\section{RESULTS}

\section{Screening of macrolide derivatives inhibiting MPO release from neutrophils}

MPO mediates the production of hypochlorous acid that can cause significant tissue damage. ${ }^{24}$ We previously elucidated that the absence of MPO activity alleviate pneumonia pathology and viral load during PR-8 virus infection. ${ }^{29}$ On the basis of this finding, we first checked which macrolide derivatives inhibit MPO release in neutrophils to determine the best candidates for investigation by concomitant use of bacterial $N$-formyl methionyl peptide, formyl-methionyl-leucyl phenylalanine and actin polymerization inhibitor, cytochalasin B. We examined 1056 compounds from our macrolide compound library and selected eight candidates that showed negative regulation of MPO release in both human and mouse neutrophils using in vitro screening. $\mathrm{LM}-\mathrm{A}_{3}$ and SPM of the 16-membered macrolides, and the 12-membered EM900 (has lost anti-bacterial activity via chemical conversion from erythromycin $A ;{ }^{32,33}$ see Supplementary Figure S1), showed the highest inhibitory activity. We compared the activity of these three macrolides and CAM, a 14membered macrolide possessing anti-influenza virus activity. ${ }^{18-20}$ In addition to CAM, LM-A 3 , SPM and EM900 inhibited MPO release from human neutrophils (Supplementary Figure S2). LM-A 3 , SPM and CAM are known to be anti-bacterial agents. ${ }^{17}$ The $\mathrm{LD}_{50}$ and MIC of these macrolides are shown in Table 1. These results suggest that the macrolides inhibited MPO release, regardless of whether they had anti-bacterial activity or not.

\section{Effect of treatment with macrolide derivatives on survival rate and} body weight variability

The PR-8 virus strain induces severe and fatal respiratory disease in mice. ${ }^{27,34,35}$ Using an experimental procedure that led to $100 \%$ fatality 7-14 days after intranasal infection with a sublethal dose (320 plaqueforming units) of PR-8 virus, the survival rate and body weight, in the presence or absence of each macrolide, were monitored (Figure 1). In the PBS-injected control group, all of the mice died within 2 weeks after the infection (Figure 2a). In contrast, injection of LM-A 3 markedly enhanced the survival rate of infected mice with a significant difference $(P<0.0001)$ and $80.9 \%$ of the mice survived at 14 days post infection. LM- $A_{3}$ delayed weight loss for 1-6 days after infection (Figure $2 b$ ). The injection of SPM and EM900 also delayed body weight loss up to 6 days post infection, but their positive effect on survival rate was lower than that of $\mathrm{LM}_{-} \mathrm{A}_{3}$; survival rates of SPM and EM900 were $33.3 \%$ and $27.2 \%$ with significant differences $P=0.0204$ and $P=0.0168$, respectively (Figure 2). Injection of CAM, however, neither induced the enhanced survival effect nor the delay of weight loss in this model (Figure 2). These results indicate that the 12-membered and 
Table 1 Biological activity ( $\mathrm{LD}_{50}$, cytotoxicity and MIC) of each macrolide used in this study

\begin{tabular}{|c|c|c|c|c|c|c|c|}
\hline & $L M-A_{3}$ & & $S P M$ & & $C A M$ & & EM900 \\
\hline & Mouse & & Mouse & & Mouse & & Rat \\
\hline \multicolumn{8}{|l|}{$L D_{50}\left(m g k^{-1}\right)$} \\
\hline i.p. & 780 & & 322 & & 850 & & - \\
\hline i.v. & 385 & & 130 & & 173 & & - \\
\hline Oral & 6400 & & 2900 & & 1230 & & $>2000$ \\
\hline s.c. & $>3000$ & & 1470 & & $>5000$ & & - \\
\hline \multicolumn{8}{|l|}{$M I C\left(\mu g m I^{-1}\right)$} \\
\hline \multicolumn{8}{|l|}{$\operatorname{Gram}(+)$} \\
\hline S. aureus ${ }^{\mathrm{a}}$ & $0.39-1.56$ & S. aureus FDA209pa & 1 & S. aureus FDA209PJC- $1^{\mathrm{a}}$ & 0.12 & S. aureus FDA209a & $>128$ \\
\hline S. pneumoniae ${ }^{\mathrm{a}}$ & 0.78 & S. aureus ISP447ª & 4 & S. pneumoniae IID553ª & $\leqslant 0.06$ & S. aureus Smith ${ }^{a}$ & $>128$ \\
\hline S. pyogenes ${ }^{\mathrm{a}}$ & 0.19 & S. aureus Smith ${ }^{\mathrm{a}}$ & 4 & S. pneumoniae IID554a & $\leqslant 0.06$ & S. aureus $8325(\mathrm{pET} 2104)^{a}$ & $>128$ \\
\hline \multirow[t]{3}{*}{ E. faecalis ${ }^{\mathrm{b}}$} & 3.13 & E. faecalis ATCC $21212^{\mathrm{b}}$ & 0.5 & S. epidermidis IID866a & 0.12 & S. epidermidis IFO12648 & $>128$ \\
\hline & & M. Iuteus ATCC9341c & $\leqslant 0.25$ & S. pyogenes IID689a & $\leqslant 0.06$ & M. Iutenus ATCC $21212^{\mathrm{C}}$ & 128 \\
\hline & & MRSA N315 IR94d & $>128$ & P. anaerobius ATCC $27337^{\mathrm{e}}$ & $\leqslant 0.06$ & & \\
\hline \multicolumn{8}{|l|}{$\operatorname{Gram}(-)$} \\
\hline N. gonorrhoeae & $0.09-3.13$ & E. cloacae IF013535g & $>128$ & H. pylori ATCC $43504^{\mathrm{h}}$ & $\leqslant 0.06$ & E. coli $\mathrm{NIHJ} J \mathrm{~J}-2^{\mathrm{i}}$ & $>128$ \\
\hline N. meningitidis ${ }^{f}$ & $0.04-12.5$ & E. aerogen NCTC10006g & $>128$ & H. pylori ATCC $43629^{h}$ & 0.12 & K. pneumoniae NCTN9632 & $>128$ \\
\hline E. coli ${ }^{i}$ & 100 & P. mirabilic IFO3849k & $>128$ & H. pylori ATCC $43579^{h}$ & $\leqslant 0.06$ & S. marcescens IFO12648 & $>128$ \\
\hline C. $s p p .^{\mathrm{m}}$ & $0.39-0.78$ & P. vulgaris OX-19k & $>128$ & L. pneumophilia ATCC33152n & 0.015 & E. aerogen NCTC10006g & $>128$ \\
\hline M. pneumoniae ${ }^{0}$ & $0.015-0.03$ & E. coli $\mathrm{NIHJ} J \mathrm{~J}-2^{\mathrm{i}}$ & $>128$ & L. pneumophilia ATCC33215n & 0.015 & A. calcoaceticus IFO2552p & $>128$ \\
\hline K. pneumoniaej & 25 & C. freundii ATCC8090q & $>128$ & M. catarrhalis ATCC $25238^{r}$ & $\leqslant 0.06$ & & \\
\hline \multirow[t]{5}{*}{ P. vulgaris ${ }^{k}$} & $>100$ & K. pneumoniae NCTN9632 & 128 & H. influenzae IID988 & 4 & & \\
\hline & & M. morganii IID Konot & $>128$ & N. gonorrhoeae ATCC49226 & 1 & & \\
\hline & & S. marcescens IFO12648 & $>128$ & C. jejuni ATCC $33560^{\mathrm{m}}$ & 2 & & \\
\hline & & $P$. aeruginosa $46001^{u}$ & $>128$ & C. trachomatis $\mathrm{D} / \mathrm{UW}-3 / \mathrm{Cx}^{v}$ & 0.03 & & \\
\hline & & A. calcoaseticus IFO2552p & 64 & M. pneumoniae $\mathrm{FH}^{\circ}$ & 0.002 & & \\
\hline
\end{tabular}

Abbreviations: CAM, clarithromycin; LM- $\mathrm{A}_{3}$, leucomycin A3; SPM, spiramycin.

The information of LD 50 of LM- $A_{3}$, SPM and CAM was published data by Santa Cruz Biotechnology as follows: LM-A (Josamycin): http://datasheets.scbt.com/sc-351855.pdf; SPM: http://

datasheets.scbt.com/sc-251064.pdf; and CAM: http://datasheets.scbt.com/sc-205634.pdf. The LD50 of EM900 was examined using a rodent by T. Sunazuka et al. (unpublished data).

as: Staphylococcus.

b: Enterococcus.

'M: Micrococcus.

${ }^{d}$ MRSA: methicillin-resistant Staphylococcus aureus.

e P: Peptostreptcoccus.

${ }^{\mathrm{f}} \mathrm{N}$ : Neisseria.

$\mathrm{g}_{\text {E: Enterobacter. }}$

${ }^{\mathrm{h}} \mathrm{H}$ : Helicobacter.

i E: Escherichia.

j $\mathrm{K}$ : Klebsiella.

kP: Proteus.

'S: Serratia.

m $\mathrm{m}$ : Campylobacter.

nL: Legionella.

$\mathrm{M}$ : Mycoplasma.

PA: Acinetobacter.

${ }^{\mathrm{q}} \mathrm{C}$ : Citrobacter.

'M: Moraxella.

${ }^{\mathrm{s}} \mathrm{H}$ : Haemophilus.

${ }^{\mathrm{t}} \mathrm{M}$ : Morganella.

uP: Pseudomonas.

${ }^{\vee} \mathrm{C}$ : Chlamydia.

16-membered macrolides tested produced a significant survival effect in animals exposed to lethal infection with influenza A virus.

\section{Pathology in the lung treated with macrolide derivatives}

We next performed histological observations in the lungs of macrolide-treated mice removed 6 days after infection (Figure 3a). In comparison with an uninfected, healthy mouse, the lung of infected control mice displayed severe inflammatory pathology with significant infiltration of inflammatory cells, interstitial edema and thickening in alveolar walls. The administration of $\mathrm{LM}_{-} \mathrm{A}_{3}$ alleviated this severe pathology in the lung, whereas such alleviation was not observed by SPM or CAM treatment. These results suggest that $\mathrm{LM}-\mathrm{A}_{3}$ reduces severe inflammatory disease induced by influenza A virus infection.

\section{Regulatory effects of macrolide derivatives on MPO activity in BALF}

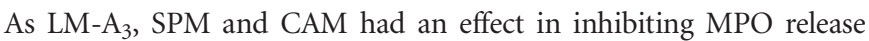
from neutrophils in vitro, we measured MPO activity in the BALF of infected mice treated with or without macrolide compounds. MPO activity in the BALF markedly increased at 3 days and then decreased to basal level by 6 days post infection in PBS-injected control mice (Figure $3 \mathrm{~b}$ ). This result indicates that MPO activity increases in the BALF during the acute phase of influenza A virus infection. We found that MPO activity in the BALF of $L M-A_{3}$-injected mice was less than that of control mice with a significant difference (Figure 3b). Injection of CAM inhibited the MPO activity to a similar extent compared with the level of $\mathrm{LM}-\mathrm{A}_{3}$, whereas an increasing tendency for MPO activity was shown in SPM-injected mice at this time point. However, statistical differences from the level of control by these two compounds were not observed at this time point (Figure 3b). There were no significant differences in the activities at 6 days post infection between macrolide-injected and control mice. These results suggest that the negative regulation of MPO activity is a likely explanation for the protection from aggravation of pneumonia by $\mathrm{LM}^{-\mathrm{A}_{3}}$ in the setting of influenza $\mathrm{A}$ virus infection. 


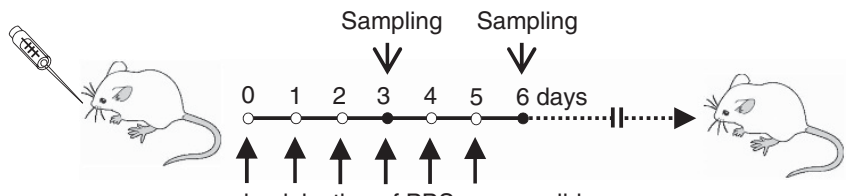

Intranasal infection i.p. injection of PBS or macrolide

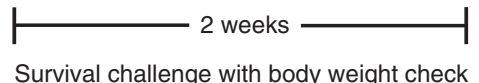

Figure 1 Scheme of a procedure for infection experiment. Mice were infected intranasally with PR-8 A/H1N1 influenza virus. After the infection, mice were i.p. injected with $250 \mu \mathrm{l}$ of macrolide-EtOH/D-PBS diluent or control (without macrolide compound) at one shot per day for 5 days. The $250 \mu \mathrm{l}$ diluent includes $66 \mu \mathrm{g}$ each of macrolide as described in Materials and Methods. Sample collections were performed at 3 and 6 days post infection. The survival challenge was carried out with body weight checks at every day for 2 weeks. A full color version of this figure is available at The Journal of Antibiotics journal online.

Inhibitory effect of macrolide derivatives on viral titer in the lung To investigate the effects of macrolide derivatives on the replication of influenza A virus, we evaluated virus titers in lung tissue by a quantification of relative expression level of the virus $M 1$ gene. At 3 days post infection, none of the macrolides influenced M1 expression in the lung (Figure 4). LM- $\mathrm{A}_{3}$ and SPM, however, inhibited viral M1 expression in the lung at 6 days post infection with significant difference (Figure 4). CAM also showed a decreasing trend of M1 expression in the lung at 6 days. These data indicate that viral replication in the lung is comparable between PBS and macrolide treatment at 3 days, but that at least $\mathrm{LM}-\mathrm{A}_{3}$ and SPM induce viral clearance at 6 days post infection.

Effective action of macrolide derivatives on production of anti-viral and pro-inflammatory cytokines in BALF

Given the findings of histological and viral clearance, we examined cytokine production in the BALF to improve the understanding of the mechanism of action of the macrolides. As LM- $\mathrm{A}_{3}$ and SPM inhibit virus proliferation in the lung, we first investigated the production of IFN- $\alpha$ protein in the BALF (Figure 5). In control infected mice, an increase of IFN- $\alpha$ production was detected in the BALF at 3 days post infection; thereafter, in control mice it decreased at 6 days, indicating that IFN- $\alpha$ is elevated during the acute phase of the infection. LM- $\mathrm{A}_{3}$ boosted IFN- $\alpha$ production two-fold higher than controls in the acute phase (Figure 5). SPM also showed a tendency to promote IFN- $\alpha$ production, but CAM did not.

$\mathrm{LM}_{3} \mathrm{~A}_{3}$ suppressed the production of several pro-inflammatory cytokines, including tumor necrosis factor- $\alpha$ (TNF- $\alpha$ ), interleukin (IL)-1 $\alpha$, monocyte chemoattractant protein-1 (MCP-1) and eotaxin in the BALF at 3 days post infection (Figure 5). Both SPM and CAM negatively regulated the production of MCP-1 and eotaxin in the BALF, and SPM showed a tendency to reduce TNF- $\alpha$ level in addition, but two macrolides showed no significant differences of these cytokine productions. Interestingly, LM- $\mathrm{A}_{3}$ enhanced IL-6, granulocyte-macrophage colony-stimulating factor and macrophage inflammatory protein-1 $\beta$ production at 6 days post infection (Figure 5). No effective differences of production regarding other measured cytokines were observed by LM- $\mathrm{A}_{3}$ treatment in comparison with the other two macrolides (Supplementary Figure S3). Only CAM decreased the production of macrophage inflammatory protein2 , platelet-derived growth factor $\mathrm{BB}$ and vascular endothelial growth factor at 3 days post infection (Supplementary Figure S3). SPM and

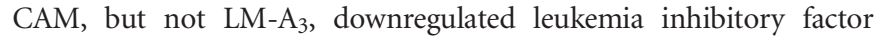
production in the BALF on day 6 (Supplementary Figure S3).

In essence, $\mathrm{LM}^{-\mathrm{A}_{3}}$ suppressed the production of several proinflammatory cytokines, including TNF- $\alpha$, IL- $1 \alpha$, MCP- 1 and eotaxin, in the BALF at 3 days post infection, whereas SPM and CAM did not influence the production levels of these cytokines at all (Figure 5). Similarly, LM-A 3 enhanced IL-6, granulocyte-macrophage colonystimulating factor and macrophage inflammatory protein- $1 \beta$ production at 6 days post infection, whereas both SPM and CAM did not (Figure 5). No effective differences of production regarding other measured cytokines were observed by $\mathrm{LM}-\mathrm{A}_{3}$ treatment in comparison with the other two macrolides (Supplementary Figure S3).

Inhibitory role of macrolide derivatives in virus activity in human host cells

We attempted to focus on whether the tested macrolide compounds have direct anti-influenza virus effects in human lung epithelial cells, because observations have indicated that influenza $\mathrm{A} / \mathrm{H} 1 \mathrm{~N} 1$ and $\mathrm{A} /$ $\mathrm{H} 5 \mathrm{~N} 1$ viruses attach and invade lung epithelial cells in humans. ${ }^{9,20}$ Thus, we used a human alveolar type II-derived carcinoma line, A549 cells, to elucidate the medicinal effect of these macrolide derivatives. A remarkable increase in the copy number of M1 nucleotides of PR-8 virus was detected in the A549 cells within $48 \mathrm{~h}$ after the infection (Figure 6a). Administration of $\mathrm{LM}-\mathrm{A}_{3}, \mathrm{SPM}$ or CAM suppressed the increase of the viral nucleotide inside A549 cells in a dose-dependent manner (Figure $6 \mathrm{~b}$ ). LM- $\mathrm{A}_{3}$ was particularly effective in reducing influenza $A$ virus proliferation and a significant reduction in copy numbers of M1 nucleotides was observed at low dose $\left(12.5 \mu \mathrm{g} \mathrm{ml}^{-1}\right)$. No observation of cell death was seen in A549 cells after treatment of any of the macrolides used in this study. As the enhancement of IFN- $\alpha$ production in BALF after injection of LM- $\mathrm{A}_{3}$ was observed in our in vivo experiment (Figure 5), it was speculated that IFN- $\alpha$ is similarly associated with the inhibitory effect on viral replication in human A549 cells. Contrary to our expectation, a significant increase of human IFN- $\alpha$ production was not detected in the culture supernatant of A549 cells co-cultured with LM-A $\mathrm{A}_{3}$ after $48 \mathrm{~h}$ (Supplementary Figure S4).

\section{DISCUSSION}

The stimulation of neutrophils by formyl-methionyl-leucyl phenylalanine and cytochalasin B evokes a significant degranulation with exocytosis of azurophil granules containing MPO. ${ }^{25,36,37}$ The cytochalasin B binds to the positive $(+)$ end of microfilament F-actin and disturbs actin polymerization (Supplementary Figure S5). The peripheral actin mesh surrounds neutrophil granules and limits access of granules to the cytoplasmic face adjacent to the plasma membrane with respect to neutrophil activity. ${ }^{38,39}$ The cytochalasin B is generally thought to break up this 'barrier' function, but not hamper neutrophil activation. ${ }^{38}$ Several macrolides, for example, Kabiramide $\mathrm{C}$ and aplyronine $\mathrm{A}$, bind to $\mathrm{G}$-actin and interfere with the dynamics of cytoskeletal actin polymerization. ${ }^{40,41} \mathrm{LM}^{-\mathrm{A}_{3}}$, SPM, CAM and EM900 screened in this study, might have competitive or other unknown functions to cytochalasin B-induced degranulation (Supplementary Figure S5). In addition, macrolide compounds, including CAM, are known to reduce the number of acidic endosomes and inhibit acidification in the cytoplasm of mammalian host cells. $^{20,42}$ In neutrophils, cytoplasmic acidification by blockage of $\mathrm{Na}^{+} / \mathrm{H}^{+}$antiport significantly enhances degranulation of cytoplasmic azurophils containing MPO. ${ }^{43} \mathrm{LM}_{-} \mathrm{A}_{3}, \mathrm{SPM}, \mathrm{CAM}$ and EM900 may have a potential inhibitory effect on cytoplasmic acidification, resulting in the reduction of azurophilic exocytosis. 


\section{a}

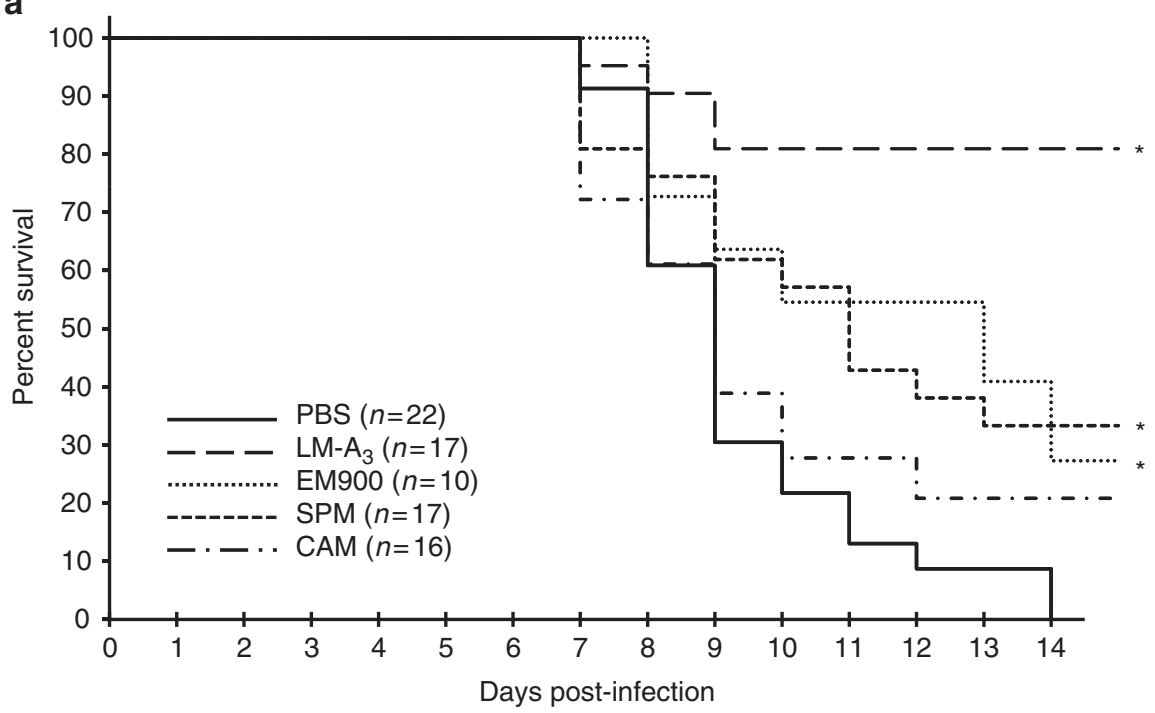

b

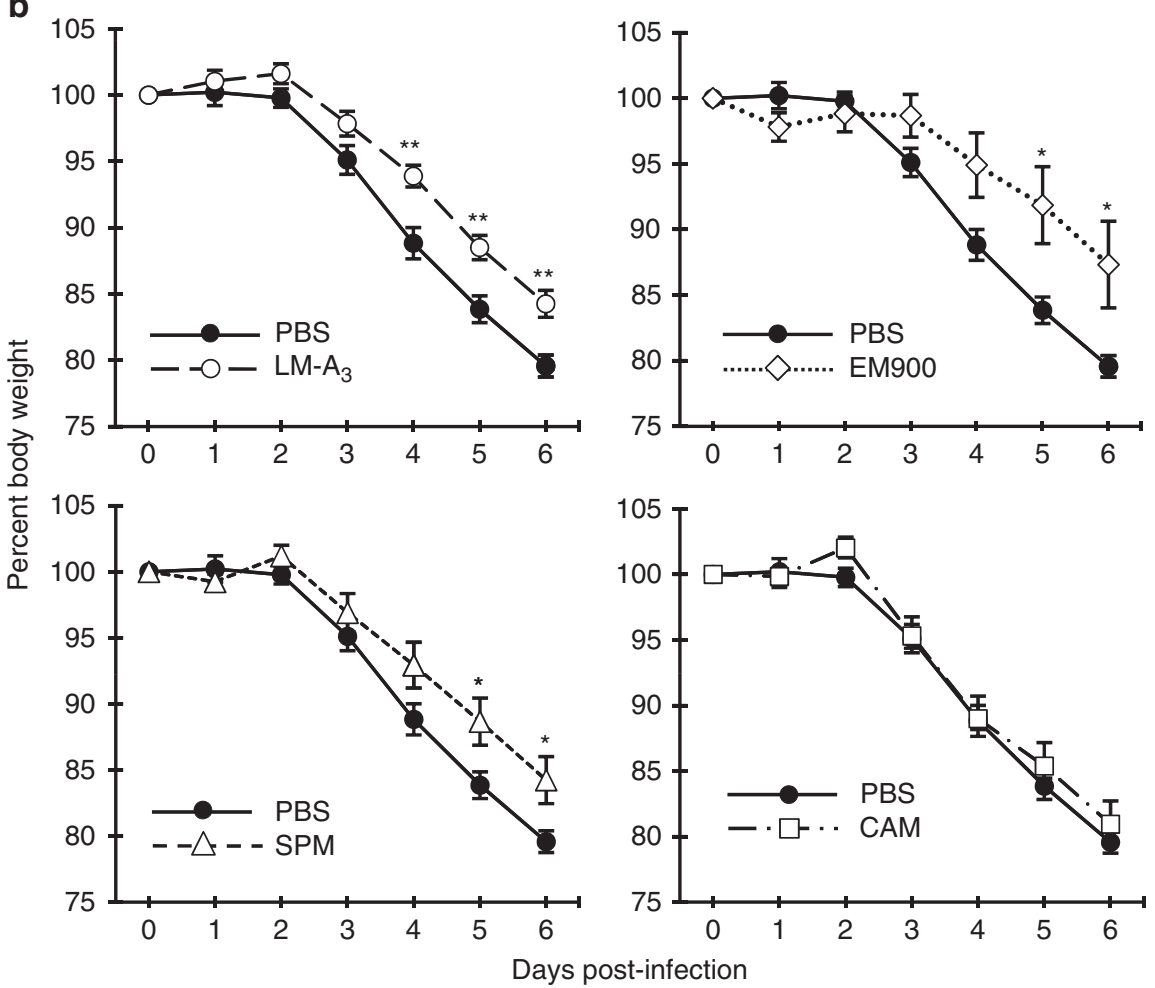

Figure 2 Effect of macrolide on the survival rate of lethally infected mice. (a) Percent survival effect of each macrolide derivative. Total number of mice in each group for survival experiment is shown in the figure. The survival curve of each group was drawn by the Kaplan-Meier method with cumulative survival rate. The log-rank (Mantel-Cox) test was used for the comparison of survival probability between PBS- and each macrolide-injected group. (b) Body weight change of each mouse group. Data are expressed as a percentage of mean \pm s.e. starting weight. ${ }^{*} P<0.05$ and ${ }^{* *} P<0.01$ (Mann-Whitney $U$-test).

MPO, which is released extracellularly from activated neutrophils and mediates hypochlorous acid production, has been implicated as a cause of pathogenesis of severe respiratory disease induced by influenza $\mathrm{A} / \mathrm{H} 1 \mathrm{~N} 1$ and $\mathrm{A} / \mathrm{H} 5 \mathrm{~N} 1$ viruses. $^{26-28}$ To inhibit $\mathrm{MPO}$ release following lethal infection with influenza A virus, we screened LM-A $A_{3}$, SPM, EM900 and CAM as inhibitors of MPO release from human and mouse neutrophils in vitro. In infected mice, LM-A produced $>80 \%$ survival effect at 14 days post infection. SPM and EM900 showed a lower survival rate of $\sim 30 \%$, in addition to delaying weight loss, whereas injection of CAM induced neither the enhanced survival effect nor the delay of weight loss. Treatment of infected mice with $\mathrm{LM}-\mathrm{A}_{3}$ also alleviated pneumonia pathology at 6 days post infection, whereas injection of SPM or CAM did not induce alleviation of the pneumonia pathology. In contrast to our study, it has been reported that oral administration of CAM into mice infected with PR-8 viruses decreases mortalities concomitant with suppression of virus titer in the lung. ${ }^{18}$ In that study, however, administration of $\mathrm{CAM}$ at $20 \mathrm{mg}$ per mouse per day reduced the mortality of infected 


\section{a}

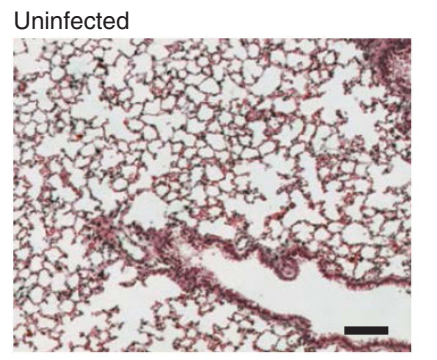

LM-A

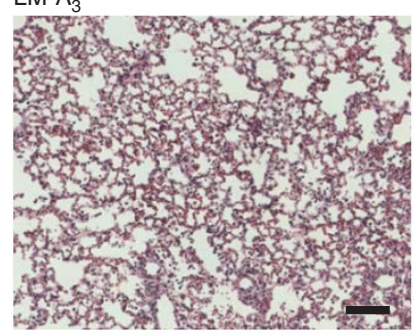

CAM

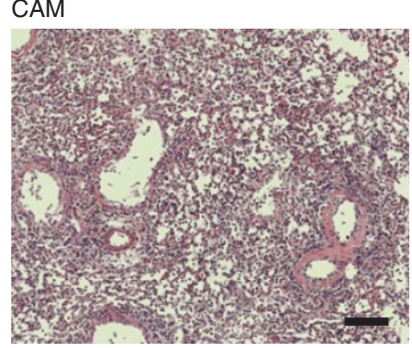

b

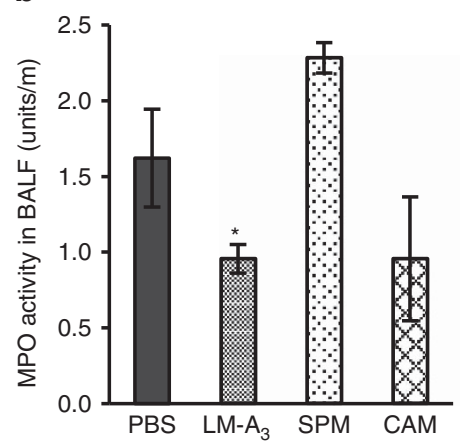

PBS

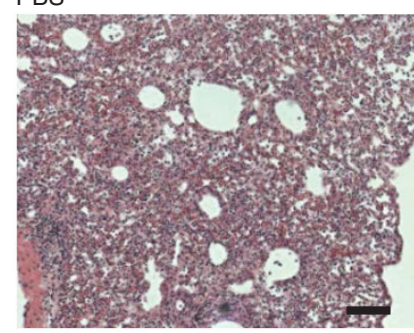

SPM

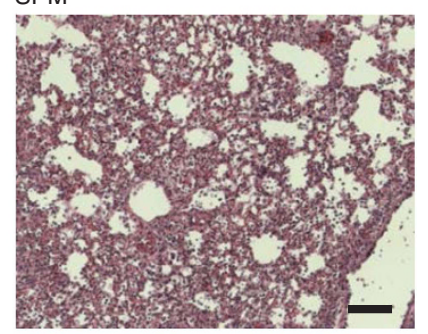

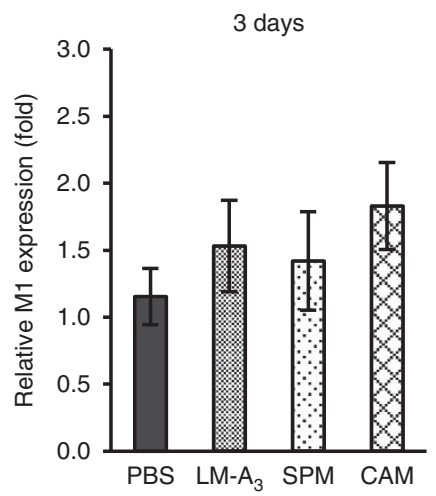

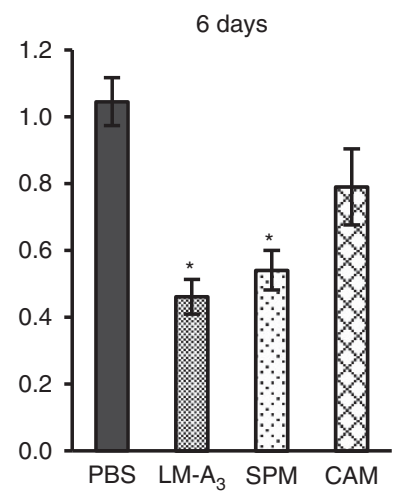

Figure 4 Virus gene expression in the lung tissue. Relative expression of virus $M 1$ gene in the lung tissue at 3 and 6 days post infection was compared between PBS- and each macrolide-injected group. The expression of M1 was normalized by the expression level of glyceraldehyde-3phosphate dehydrogenase (GAPDH) mRNA. Data are expressed as mean \pm s.e. of results from more than three individuals (PBS: $n=5, L M-A_{3}$ : $n=5$, SPM: $n=3$ and CAM: $n=3$ ) at 3 days post infection and six individuals (PBS: $n=8, \mathrm{LM}_{3}: n=8$, SPM: $n=8$ and CAM: $n=6$ ) at 6 days post infection. ${ }^{*} P<0.05$ (Student's $t$-test).

administration probably affect the anti-influenza A virus activity, accounting for differences observed between previous results and ours.

Our results showed that the high survival rate occurring as a result of the alleviation of severe pneumonia following $\mathrm{LM}-\mathrm{A}_{3}$ treatment is correlated with the reduction of MPO activity in the BALF during the acute phase of the infection. These results strongly suggest that the blockade of MPO release in neutrophils affords protection from pneumonia exacerbation following the proliferation of influenza A virus, which is consistent with our previous findings using MPO knockout mice. ${ }^{29}$ As with LM-A 3 , SPM and CAM also inhibited MPO release in vitro; however, they failed to reduce MPO activity in the BALF of infected mice. The reasons why they did not reduce in vivo are unclear but the doses used for treatment may not be sufficient for SPM and CAM to decrease MPO activity in vivo.

In this study, treatment with the macrolides led to changes in several cytokine production profiles in the BALF of infected mice. The significant differences between cytokine and MPO activity levels were not observed in the BALF when each individual status was compared (data not shown). This suggests that blockage of MPO release probably does not affect cytokine production by itself. The detailed mechanism for cytokine induction by macrolides was not investigated in the present study and remains unknown. Several in vitro studies indicate that macrolides induce a regulatory role on cytokine production after viral infection. ${ }^{44,45}$ CAM shows an inhibitory effect on inflammatory cytokine production concomitant with the reduction of nuclear factor- $\kappa \mathrm{B}$ protein level in the influenza virus infection. ${ }^{20}$ This in vitro observation suggests that macrolide directly affect cytokine productivity via nuclear factor- $\kappa \mathrm{B}$ proteins in the host cells. It is possible that $\mathrm{LM}-\mathrm{A}_{3}$ and SPM also regulate cytokine production in the lung mediating nuclear factor- $\mathrm{\kappa B}$ activity by influenza virus infection. Our results show that $\mathrm{LM}-\mathrm{A}_{3}$ suppressed viral replication in the lung at 6 days post infection. The anti-viral activity is typically attributed to an anti-viral cytokine, such as type-I IFNs. A recent report, using IFN- $\alpha$ receptor-deficient mice, shows that the deficiency significantly increases viral titer in the lung and leads to total eradication of infected mice with PR- 8 virus. ${ }^{46}$ This observation indicates that IFN- $\alpha$ produced by influenza virus infection disturbs

mice $(P<0.05$ by the Kaplan-Meier method), but it is ineffective at $2 \mathrm{mg}$ per mouse per day. ${ }^{18}$ The frequent high-dose administration of CAM makes the development of drug-resistant bacteria more likely because CAM retains its anti-bacterial activity. In the present study, i.p. injection of CAM into infected mice at $66 \mu \mathrm{g}$ per mouse per day showed no beneficial effects, whereas LM-A $\mathrm{A}_{3}$ and SPM induced survival effect after the same injection and dose, within the limits of $\mathrm{LD}_{50}$ (Table 1). The varieties in route and dose for CAM 

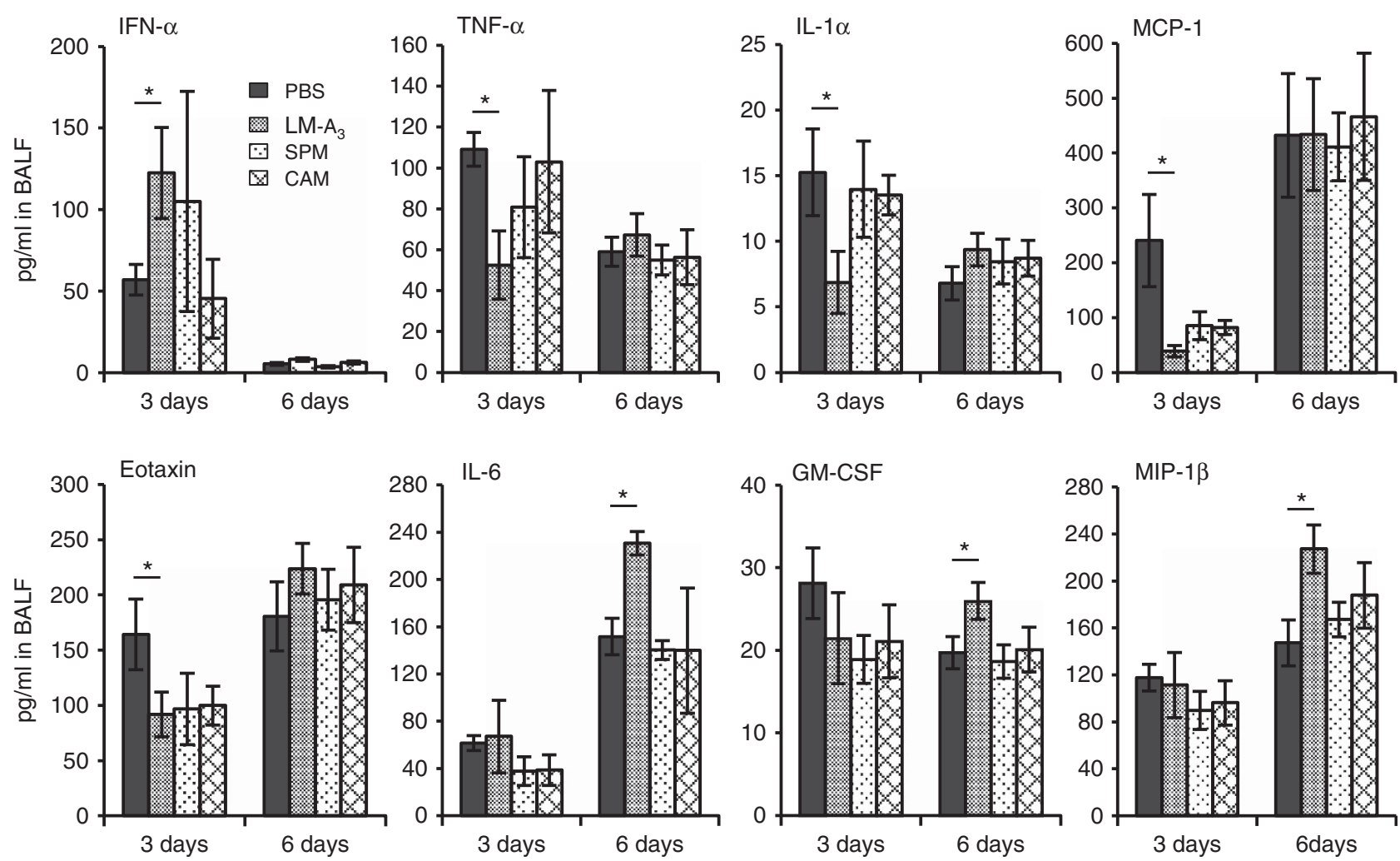

Figure 5 Cytokine productions in lung BALF. Each cytokine protein in BALF of macrolide-injected mice was quantified at 3 and 6 days post infection. The IFN- $\alpha$ production in the BALF was measured by enzyme-linked immunosorbent assay system. Other cytokine productions were quantified by the mouse Multi-plex system. Data are expressed as mean \pm s.e. of results from more than three individuals (PBS: $n=6$, LM-A $3: n=6$, SPM: $n=3$ and CAM: $n=3$ ) at 3 days post infection and six individuals (PBS: $n=12, \mathrm{LM}-\mathrm{A}_{3}: n=9$, SPM: $n=9$ and CAM: $n=6$ ) at 6 days post infection. ${ }^{*} P<0.05$ (Student's $t$-test).

a

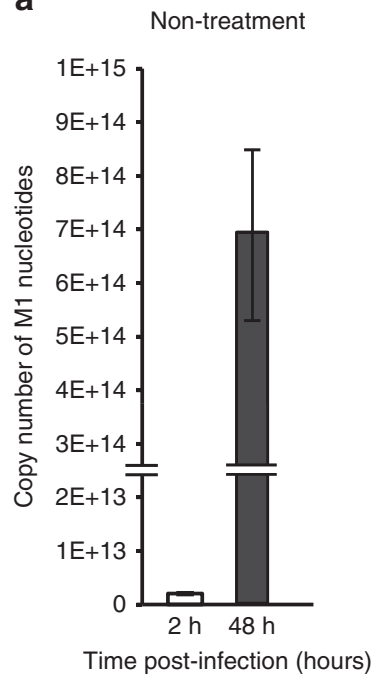

b

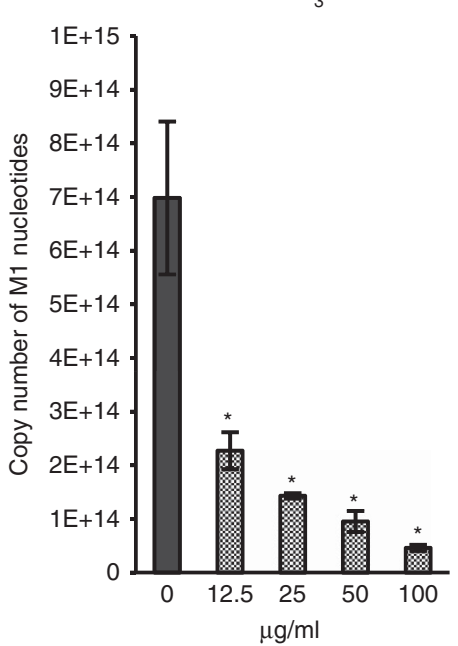

SPM

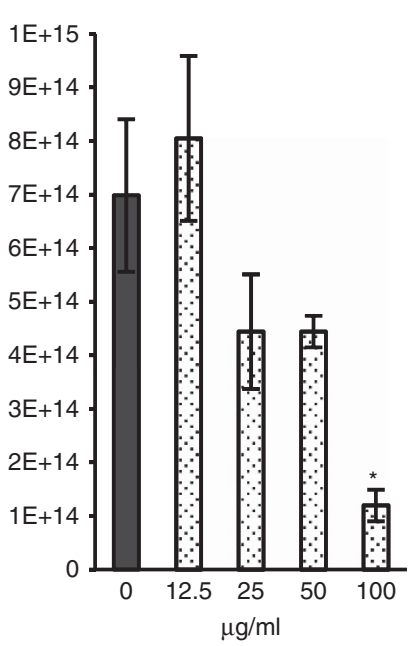

CAM

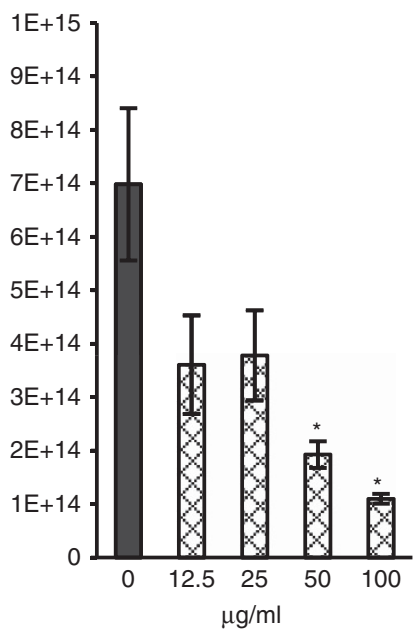

Figure 6 Copy number of virus M1 nucleotide expressed in human A549 cells. (a) The M1 copy number in A549 cells under untreated condition at 2 and $48 \mathrm{~h}$ post infection. (b) The copy numbers in the A549 cells co-cultured with various concentrations of LM-A $\mathrm{A}_{3}$ SPM or CAM for $48 \mathrm{~h}$. Data in the figure are expressed as mean \pm s.e. of results from three results. ${ }^{*} P<0.05$ (Student's $t$-test).

virus proliferation in the lung. In this study, IFN- $\alpha$ production in the BALF was indeed enhanced by LM- $\mathrm{A}_{3}$ treatment in the acute phase of infection. The reduction of viral load by $\mathrm{LM}-\mathrm{A}_{3}$ could therefore be attributed to the enhanced IFN- $\alpha$ production in the lung. The production of pro-inflammatory cytokines such as TNF- $\alpha$, IL- $1 \alpha$, eotaxin and MCP-1 in the BALF is usually elevated following replication of the influenza A virus in the lung and is implicated in the severity of respiratory disease. ${ }^{7,47,48}$ The treatment with $\mathrm{LM}-\mathrm{A}_{3}$ suppressed TNF- $\alpha$ production in the BALF, whereas SPM or CAM treatment did not significantly affect the production in the infection. 
In influenza virus infection, a blockade of interaction of TNF- $\alpha$ and its receptors prevents weight loss in mice. ${ }^{47}$ Moreover, IL- $1 \alpha$, eotaxin and MCP-1 were also reduced in the BALF after LM- $\mathrm{A}_{3}$ treatment. The IL-1 in the lung induced by influenza A virus infection has an essential role in neutrophil recruitment, leading to pneumonia pathogenesis. ${ }^{34}$ In fact, a blockade of IL-1 function by IL-1 receptor deficiency alleviates influenza viral pneumonia. ${ }^{34}$ Eotaxin and MCP-1 increase during the influenza virus infection and are thought to evoke pneumonia pathology. ${ }^{26,49}$ The inflammatory role of MCP-1 in PR-8 virus infection is also supported by an in vitro study using lung epithelial cells. ${ }^{50}$ In the present study, we found that $\mathrm{LM}-\mathrm{A}_{3}$ treatment markedly reduced production of pro-inflammatory cytokines (TNF$\alpha$, IL- $1 \alpha$, eotaxin and MCP- 1 ) in the BALF of infected mice. Thus, it can be assumed that the negative regulation of these proinflammatory cytokines in addition to the inhibition of MPO release and enhancement of IFN- $\alpha$ production by $\mathrm{LM}-\mathrm{A}_{3}$ treatment inhibits influenza pneumonia.

Furthermore, IL-6 has been thought to be implicated in increasing influenza pathogenesis. However, murine studies indicate that IL-6 does not contribute significantly to the severe pneumonia pathogenesis of $\mathrm{H} 5 \mathrm{~N} 1$ influenza virus. ${ }^{47,51} \mathrm{~A}$ recent report, using IL-6-deficient mice and PR- 8 virus, showed that IL-6 is a vital innate immune cytokine providing a protective role in influenza A virus infection. ${ }^{35}$ In fact, the absence of IL-6 results in the total disappearance of infected mice with severe exacerbation of pneumonia pathology. In our study, $\mathrm{LM}^{-\mathrm{A}_{3}}$ did not inhibit IL-6 production in the BALF at 3 days post infection, rather it enhanced production at 6 days post infection. The enhanced IL- 6 following LM$\mathrm{A}_{3}$ treatment at 6 days may have a beneficial protective role against virus proliferation and pneumonia severity induced by influenza $\mathrm{A}$ virus infection.

The in vitro study using a human alveolar epithelial cell line, A549 cells, clearly showed that LM-A 3 , SPM and CAM had a direct inhibitory effect on viral proliferation in human host cells. The

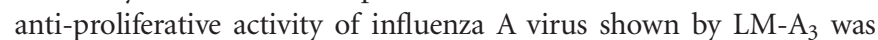
higher than that of CAM and SPM. Unlike the in vivo situation using mice, a remarkable increase of human IFN- $\alpha$ production was not detected in the culture supernatant of A549 cells co-cultured with each macrolide (Supplementary Figure S4). This in vitro observation indicates that macrolides, including $\mathrm{LM}-\mathrm{A}_{3}$, possess the ability to inhibit virus proliferation without much contribution from IFN- $\alpha$. Several immune cell types, including macrophages, dendritic cell subsets and immature Antigen-presenting cells, are known to produce the IFN- $\alpha$ following influenza virus infection..$^{52-55}$ These observations suggest that $\mathrm{LM}-\mathrm{A}_{3}$ encourages such immune cells to promote IFN- $\alpha$ production in vivo during the influenza virus infection. Influenza viruses are internalized by receptor-mediated endocytosis after binding on the host cell surface, and the low $\mathrm{pH}$ condition in the endosome triggers fusion of viral and endosomal membranes for the next process of viral replication. ${ }^{56,57}$ Macrolides, including $\mathrm{CAM}$ and bafilomycin $\mathrm{A} 1$, reduce the number of acidic endosomes and decrease viral propagation in host cells infected by influenza $\mathrm{A}$ virus. ${ }^{20,58} \mathrm{LM}^{-\mathrm{A}_{3}}$ and SPM are also suggested to exert an inhibitory effect on acidification in cytoplasmic endosomes, thereby disturbing viral proliferation inside A549 cells. Our study demonstrated that $\mathrm{LM}_{3} \mathrm{~A}_{3}$ was a most effective 16-membered macrolide, possessing highly effective anti-influenza viral properties in human cells in vitro as well as in mouse in vivo. Consequently, LM- $\mathrm{A}_{3}$ is a promising lead compound candidate for the development of a drug for treatment of influenza-induced respiratory disease in humans.
In conclusion, of 1056 macrolides screened for inhibition of MPO release, $\mathrm{LM}-\mathrm{A}_{3}$ produced the highest survival effect in infected mice, concomitant with the reduction of both viral load and pneumonia. We ascertained that the beneficial effects by $\mathrm{LM}-\mathrm{A}_{3}$ are attributable to the negative regulation of MPO activity and pro-inflammatory cytokines, as well as with the enhancement of IFN- $\alpha$ production. This 16-membered macrolide also possessed direct anti-influenza A virus activity in human alveolar epithelial cells. These observations indicate that $\mathrm{LM}-\mathrm{A}_{3}$ is not only a promising candidate molecule for the development of a new drug for the treatment of human respiratory disease induced by influenza virus, it also offers promise against the recently emerged avian A/H7N9 virus. Moreover, our data using EM900 suggests that a pharmacological architecture can be manipulated to bestow or remove anti-bacterial and anti-influenza virus activity. We have shown that it is possible to develop novel macrolide derivatives that have high anti-influenza virus activity without anti-bacterial properties. Further work to better understand the pharmacology and mode of action of $\mathrm{LM}-\mathrm{A}_{3}$ with respect to influenza virus infection and disease is required in order to develop this promising candidate into an effective anti-influenza drug.

\section{CONFLICT OF INTEREST}

The authors declare no conflict of interest.

\section{ACKNOWLEDGEMENTS}

This study was supported by a Research-in-Aid Grant from the Ministry of Health, Labor and Welfare of Japan (H22-S-I-014) and the Health Science Foundation of Japan (H21-004).

1 Glezen, W. P., Taber, L. H., Frank, A. L., Gruber, W. C. \& Piedra, P. A. Influenza virus infections in infants. Pediatr. Infect. Dis. J. 16, 1065-1068 (1997).

2 World Health Organization (WHO). Influenza (seasonal) fact sheet No. 211. Downloaded from http://www.who.int/mediacentre/factsheets/fs211/en/index.html (2009)

3 Luk, J., Gross, P. \& Thompson, W. W. Observations on mortality during the 1918 influenza pandemic. Clin. Infect. Dis. 33, 1375-1378 (2001).

4 Tumpey, T. M. et al. Characterization of the reconstructed 1918 Spanish influenza pandemic virus. Science $\mathbf{3 1 0}, 77-80$ (2005)

5 Centers for Disease Control and Prevention (CDC). Cases of influenza A (H5N1)Thailand, 2004. MMWR Morb. Mortal. Wkly Rep. 53, 100-103 (2004).

6 Tran, T. H. et al. Avian influenza A (H5N1) in 10 patients in Vietnam. N. Engl. J. Med. 350, 1179-1188 (2004).

7 Kobasa, D. et al. Aberrant innate immune response in lethal infection of macaques with the 1918 influenza virus. Nature 445, 319-323 (2007).

8 Kawachi, S. et al. Risk parameters of fulminant acute respiratory distress syndrome and avian influenza (H5N1) infection in Vietnamese children. J. Infect. Dis. 200, 510-515 (2009).

9 Nakajima, N. et al. The first autopsy case of pandemic influenza (A/H1N1pdm) virus infection in Japan: detection of a high copy number of the virus in type II alveolar epithelial cells by pathological and virological examination. Jpn J. Infect. Dis. 63, 67-71 (2010).

10 Mauad, T. et al. Lung pathology in fatal novel human influenza A (H1N1) infection. Am. J. Respir. Crit. Care Med. 181, 72-79 (2009).

11 Takeda, S. et al. Extracorporeal membrane oxygenation for 2009 influenza $A(H 1 N 1)$ severe respiratory failure in Japan. J. Anesth. 26, 650-657 (2012).

12 Beigel, J. \& Bray, M. Current and future antiviral therapy of severe seasonal and avian influenza. Antiviral. Res. 78, 91-102 (2008).

13 Hayden, F. G. \& Straus, S. E. Use of the oral neuraminidase inhibitor oseltamivir in experimental human influenza. JAMA 282, 1240-1246 (1999).

14 Stephenson, I. et al. Neuraminidase inhibitor resistance after oseltamivir treatment of acute influenza A and B in children. Clin. Infect. Dis. 48, 389-396 (2009).

15 Hurt, A. C., Holien, J. K., Parker, M., Kelso, A. \& Barr, I. G. Zanamivir-resistant influenza viruses with a novel neuraminidase mutation. J. Virol. 83, 10366-10373 (2009).

16 Izumi, Y., Tokuda, K., O’Dell, K. A., Zorumski, C. F. \& Narahashi, T. Synaptic and behavioral interactions of oseltamivir (Tamiflu) with neurostimulants. Hum. Exp. Toxicol. 27, 911-917 (2008).

17 Goldman, R. C. \& Scaglione, F. The macrolide-bacterium interaction and its biological basis. Curr. Drug Targets Infect. Disord. 4, 241-260 (2004). 
18 Tsurita, M. et al. Early augmentation of interleukin (IL)-12 level in the airway of mice administrated orally with clarithromycin or intranasally with IL-12 results in alleviation of influenza infection. J. Pharmacol. Exp. Ther. 298, 362-368 (2001).

19 Miyamoto, D. et al. Clarithromycin inhibits progeny virus production from human influenza virus-infected host cells. Biol. Pharm. Bull. 31, 217-222 (2008).

20 Yamaya, M. et al. Clarithromycin inhibits type A seasonal influenza virus infection in human airway epithelial cells. J. Pharmacol. Exp. Ther. 333, 81-90 (2010).

21 Ishii, H. et al. Clarithromycin has limited effects in non-elderly, non-severe patients with seasonal influenza virus A infection. J. Infect. 64, 343-345 (2012).

22 Hashimoto, Y., Moki, T., Takizawa, T., Shiratsuchi, A. \& Nakanishi, Y. Evidence for phagocytosis of influenza virus-infected, apoptotic cells by neutrophils and macrophages in mice. J. Immunol. 178, 2448-2457 (2007).

23 Yamamoto, K., Miyoshi-Koshino, T., Utsuki, Y., Mizuno, S. \& Suzuki, K. Virucidal activity and viral protein modification by myeloperoxidase: A candidate for defense factor of human polymorphonuclear leukocytes against influenza virus infection. J. Infect. Dis. 164, 8-14 (1991).

24 Klebanoff, S. J. Myeloperoxidase: friend and foe. J. Leukoc. Biol. 77, 598-625 (2005).

25 Bengtsson, T., Dahlgren, C., Stendahl, O. \& Andersson, T. Actin assembly and regulation of neutrophil function: effects of cytochalasin $B$ and retracaine on chemotactic peptide-induced $\mathrm{O}_{2}{ }^{-}$production and degranulation. J. Leuk. Biol. 49, 236-244 (1991).

26 Perrone, L. A., Plowden, J. K., Garcia-Sastre, A., Katz, J. M. \& Tumpey, T. M. H5N1 and 1918 pandemic influenza virus infection results in early and excessive infiltration of macrophages and neutrophils in the lung of mice. PLoS Pathog. 4, e1000115 (2008).

27 Crowe, C. R. et al. Critical role of IL-17RA in immunopathology of influenza infection. J. Immunol. 183, 5301-5310 (2009).

28 Van, den. Brand, J. M. et al. Comparison of temporal and spatial dynamics of seasonal H3N2, pandemic H1N1 and highly pathogenic avian influenza H5N1 virus infections in ferrets. PLoS One 7, e42343 (2012).

29 Sugamata, R. et al. Contribution of neutrophil-derived myeloperoxidase in the early phase of fulminant acute respiratory distress syndrome induced by influenza virus infection. Microbiol. Immunol. 56, 171-182 (2012).

30 Okawara, A. I. et al. Purification and characterization of aseanostatins: actinomycetederived fatty acid inhibitors to myeloperoxidase release from human polymorphonuclear leukocytes. J. Antibiot. 44, 524-532 (1991).

31 Ward, C. L. et al. Design and performance testing of quantitative real time PCR assays for influenza A and B viral load measurement. J. Clin. Virol. 29, 179-188 (2004).

32 Sugawara, A. et al. Novel 12-membered non-antibiotic macrolides from erythromycin A; EM900 series as novel leads for anti-inflammatory and/or immunomodulatory agents. Bioorg. Med. Chem. Lett. 21, 3373-3376 (2011).

33 Sugawara, A. et al. Novel 12-membered non-antibiotics macrolides, EM900 series with anti-inflammatory and/or immunomodulatory activity; synthesis, structure-activity relationships and in vivo study. J. Antibiot. 65, 487-490 (2012).

34 Schmitz, N., Kurrer, M., Bachmann, M. F. \& Kopf, M. Interleukin-1 is responsible for acute lung immunopathology but increases survival of respiratory influenza virus infection. J. Virol. 79, 6441-6448 (2005).

35 Dienz, O. et al. Essential role of IL-6 in protection against H1N1 influenza virus by promoting neutrophil survival in the lung. Mucosal. Immunol. 5, 258-266 (2012).

36 Jesaitis, A. J., Tolley, J. O. \& Allen, R. A. Receptor-cytoskeleton interactions and membrane traffic may regulate chemoattractant-induced superoxide production in human granulocytes. J. Biol. Chem. 261, 13662-13669 (1986).
37 Okawara, A. I. et al. Neutrophil contribution to the crescentic glomerulonephritis in SCG/Kj mice. Nephrol. Dial. Transplant. 19, 1708-1715 (2004).

38 Poste, G \& Allison, A. C. Membrane fusion. Biochem. Biophys. Acta 300, 421-465 (1973).

39 Ryder, M. I., Weinreb, R. N. \& Niederman, R. Microtubule-granule relationships in motile human polymorphonuclear leukocytes. Anat. Rec. 221, 679-686 (1988).

40 Tanaka, J. et al. Biomolecular mimicry in the actin cytoskeleton: mechanisms underlying the cytotoxicity of kabiramide $\mathrm{C}$ and related macrolides. Proc. Natl Acad. Sci. USA 25, 13851-13856 (2003).

41 Saito, S. et al. Novel actin depolymerizing macrolide aplyronine A. J. Biochem. 120, 552-555 (1996)

42 Ochiai, H., Sakai, S., Hirabayashi, T., Shimizu, Y \& Terasawa, K. Inhibitory effect of bafilomycin $A 1$, a specific inhibitor of vacuolar-type proton pump, on the growth of influenza A and B viruses in MDCK cells. Antiviral. Res. 27, 425-430 (1995).

43 Togashi, K., Kataoka, T. \& Nagai, K. Characterization of a series of vacuolar type H + ATPase inhibitors on CTL-mediated cytotoxicity. Immunol. Lett. 55, 139-144 (1997).

44 Jang, Y. J., Kwon, H. -J. \& Lee, B. -J. Effect of clarithromycin on rhinovirus-16 infection in A549 cells. Eur. Respir. J. 27, 12-19 (2006).

45 Morikawa, K., Zhang, J., Nonaka, M. \& Morikawa, S. Modulatory effect of macrolide antibiotics on the Th1- and Th2-type cytokine production. Int. J. Antimicrob. Agents 19, 53-59 (2002).

46 Arimori, Y. et al. Type I interferon limits influenza virus-induced acute lung injury by regulation of excessive inflammatory in mice. Antiviral Res. 99, 230-237 (2013).

47 Salomon, R., Hoffmann, E. \& Webster, R. G. Inhibition of the cytokine response does not protect against lethal H5N1 influenza infection. Proc. Natl Acad. Sci. USA 104, 12479-12481 (2007).

48 Peper, R. L. \& Campen, H. Tumor necrosis factor as a mediator of inflammation in influenza A viral pneumonia. Microb. Pathog. 19, 175-183 (1995).

49 Kawaguchi, M. et al. Expression of eotaxin by normal airway epithelial cells after influenza virus A infection. Int. Arch. Allergy Immunol. 122 (suppl 1), 44-49 (2000).

50 Phung, T. T. et al. Key role of regulated upon activation normal T-cell expressed and secreted, nonstructural protein 1 and myeloperoxidase in cytokine storm induced by influenza virus PR-8 (A/H1N1) infection in A549 bronchial epithelial cells. Microbiol. Immunol. 55, 874-884 (2011).

51 Szretter, K. J. et al. Role of host cytokine responses in the pathogenesis of avian H5N1 influenza viruses in mice. J. Virol. 81, 2736-2744 (2007).

52 Roberts, N., Hiscott, J. \& Signs, D. J. The limited role of the human interferon system response to respiratory syncytial virus challenge: analysis and comparison to influenza virus challenge. Microb. Pathog. 12, 409-414 (1992).

53 Barchet, W. et al. Dendritic cells respond to influenza virus though TLR7- and PKRindependent pathways. Eur. J. Immunol. 35, 236-242 (2005).

54 Domizio, J. D. et al. TLR7 stimulation in human plasmacytoid dendritic cells leads to the induction of early IFN-inducible genes in the absence of type I IFN. Blood 114, 1794-1802 (2009).

55 Asselin-Paturel, C et al. Mouse type I IFN-producing cells are immature APCs with plasmacytoid morphology. Nat. Immunol. 2, 1144-1150 (2001).

56 Sieczkarski, S. B., Brown, H. B \& Whittaker, G. R. Role of protein kinase C $\beta 11$ in influenza virus entry via late endosomes. J. Virol. 77, 460-469 (2003).

57 White, J., Kielian, M \& Helenius, A. Membrane fusion proteins of enveloped animal viruses. Q. Rev. Biophys. 16, 151-195 (1983).

58 Ochiai, H., Sakai, S., Hirabayashi, T., Shimizu, Y \& Terasawa, K. Inhibitory effect of bafilomycin $A 1$, a specific inhibitor of vacuolar-type proton pump, on the growth of influenza A and B viruses in MDCK cells. Antiviral. Res. 27, 425-430 (1995).

Supplementary Information accompanies the paper on The Journal of Antibiotics website (http://www.nature.com/ja) 